\title{
A patient with Charlie M Syndrome: Differential diagnosis of Oromandibular Limb Hypogenesis Syndromes
}

\author{
Ole Jung ${ }^{a, b}$, Ralf Smeets ${ }^{b}$, Henning Hanken ${ }^{b}$, Reinhard E. Friedrich ${ }^{b}$, Max Heiland ${ }^{b}$, Amir Tagniha $^{a}$, Brian Labow ${ }^{a}$
}

\begin{abstract}
Aim. In order to provide adequate treatment to a patient with a subtype of Oromandibular Limb Hypogenesis Syndromes (OLHS), this study aimed to review and to analyze the current literature and treatment options of OLHS.

Methods. Literature review in PubMed and Sciencedirect. Due to the small number of results, all available references were analyzed precisely.

Results. Cases of OLHS are formerly rare and often incomplete. There are various classifications available, which, however, often seem confusing and are of little practical relevance. Furthermore, we present a complete case report of a patient with Charlie M syndrome, a type IV (Chicarilli)/V (Hall) OLHS malformation. We also describe embryologic pathogenesis and differential diagnoses.
\end{abstract}

Conclusion. As a result of our literature review, we recommend an adjusted classification for OLHS.

Key words: Oromandibular Limb Hypogenesis Syndromes (OLHS), Charlie M Syndrome, Oromandibular and limb hypogenesis malformations (OLHM)

Received: August 1, 2015; Accepted with revision: April 8, 2016; Available online: April 27, 2016 http://dx.doi.org/10.5507/bp.2016.020

${ }^{a}$ Department of Plastic and Oral Surgery, Children's Hospital Boston, Harvard Medical School, Boston, USA ${ }^{b}$ Department of Oral and Maxillofacial Surgery, University Medical Center Hamburg, Hamburg, Germany Corresponding author: Ole Jung, e-mail: ol.jung@uke.de

\section{INTRODUCTION}

Oromandibular Limb Hypogenesis Syndromes (OLHS) describe a group of heterogeneous malformations of the face and body. In this context, the two classifications of Hall (1971) and Chicarilli et al. (1985) are shown in Tables 1 and $2^{1-11}$. Since these malformations are extremely rare, few cases have been reported in the literature to date.

Genetic causes aside, the etiology of most phenotypes is still unknown ${ }^{4,12-13}$. Amniotic bands, persistence of the embryonic membrane, teratogenic environmental factors and vascular disruptions have been discussed ${ }^{4-6,13}$. The manifestations generally appear syndrome between days 28 and 63 of the embryonic period when the extremities and face differentiation occur ${ }^{6,14}$.

The OLHS type IV (Chicarilli) and V (Hall) in particular are difficult to diagnose because they summarize various manifestations of syndromes and sequences. For instance, Möbius and Hanhart syndromes are regarded as due to genetic disposition while the Charlie M, Pierre Robin and amniotic band syndromes are either not (amniotic band), unlikely (Charlie M) or occasionally (Pierre Robin) inherited.

In this case report, we present a complete case report of a patient with the most likely diagnosis Charlie $\mathrm{M}$ syndrome. We further describe concordant and possible differential diagnoses.

\section{CASE REPORT}

A twenty-three-year-old male with severe oromandibular and limb deformities presented for mandibular augmentation at our department. Since 1995, the patient had been in multidisciplinary treatment in plastic, craniofacial, orthopedic, otopharyngological and developmental care programs.

The patient immigrated to the U. S. in 1995 by adoption. He spent the first five years of his life in a Philippine orphanage. His prenatal history revealed that his twentyfive-year-old mother became pregnant after a short term relationship. She unsuccessfully tried to abort the pregnancy by taking oral abortive drugs within the first trimester and gave birth to the patient at term. On admission, he was diagnosed with multiple oromandibular limb anomalies including cleft palate, lower lip and tongue fusion to hard palate, hypoglossia, micrognathia, only 8 single teeth of the upper jaw, one single molar at position 46 of the lower jaw, bilateral upper extremity aplasias distal to the elbow, left lower leg hemimelia distal to the calcaneus and right toe syndactyly to the $2^{\text {nd }}, 3^{\text {rd }}$ and $4^{\text {th }}$ digits. The patient's family history revealed no other incidents of congenital defects.

Previous clinical reports indicate that the patient had undergone surgery in the Philippines when the glossopalatine fusion and cleft palate were corrected. During childhood, he suffered multiple times from blocked and congenitally deformed eustachian tubes causing chronic otitis media and moderate conductional hearing loss. 
Eventually the, eustachian tubes were extended by implants.

At our department, the patient presented as a healthy, moderately built and well-nourished male with unaffected intelligence. He exhibited a clear mandible hypoplasia with an inwardly oriented lower lip, absence of lower vestibulum oris and intact cranial nerve functions III-VII with respect to functional problems to close his mouth completely. Oral examination revealed hypoglossia, posteriorthird ankyloglossia inferiorly, oligodontia with peg-shaped teeth of the upper jaw and one molar at position 46. With unaltered external skin, facial pulses were bilaterally palpable (Fig. 1a,b). The upper extremities featured bilateral transverse deficiencies at approximately 7 to $8 \mathrm{~cm}$ distal to the elbow (Fig. 2a). The lower right extremity was unaffected, while the left leg was longitudinally and transversely deficient below the ankle joint (Fig. 2b). Apropos his private life and sports activities, (college student, driver, athlete), his social life appeared normal. Given this information, he was indicated for a chin implant with combined temporoparietal fascia free flap.

During surgery, placement of a chin implant was achieved by incisional release of gingivolabial scarring of $20 \mathrm{~cm}$ squared oral area, application of a Medpor chin implant (Stryker, Kalamazoo, Michigan, USA), free temporoparietal fascial flap from the left scalp to the lower lip vestibule and local tissue arrangement of the lower lip of around 5 centimeters squared (Fig 3).

The postoperative course appeared normal regarding flap ingrowth, flap vascularization, patient mobilization and decreasing inflammation parameters (Fig. 4). Vascularization was regularly inspected by vascular doppler. We slowly introduced liquid and solid food after a couple of days. However, the patient developed large pharyngeal blot clots. For this reason, debridement and coagulation of the flap was performed in a second operation. The patient was discharged in good physical condition after 16 days.
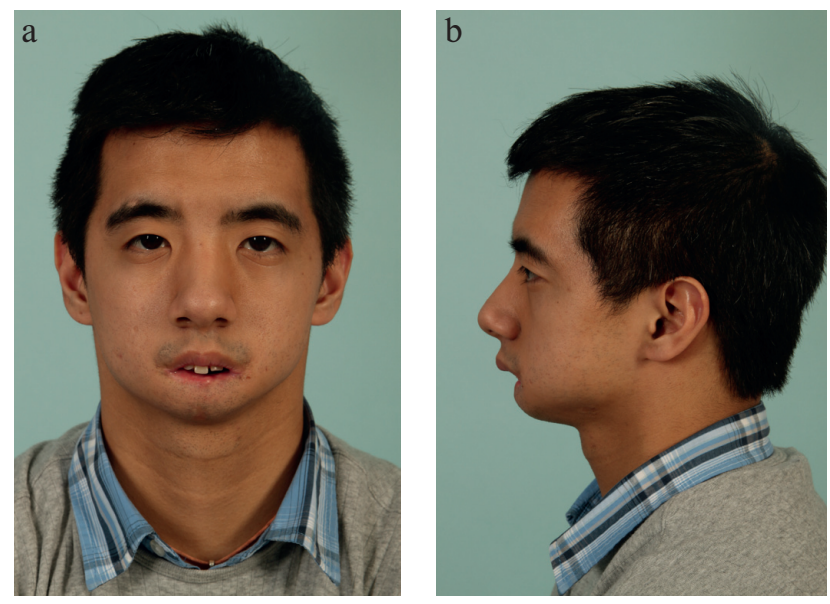

Fig. 1. a (left), b (right): Contemplation of the face revealed a hypoplastic mandible with an inwardly lower lip and absent sulcus. The patient was unable to close his mouth properly. Oral examinations showed hypoglossia, ankyloglossia only 8 teeth of the upper and one molar of the lower jaw.
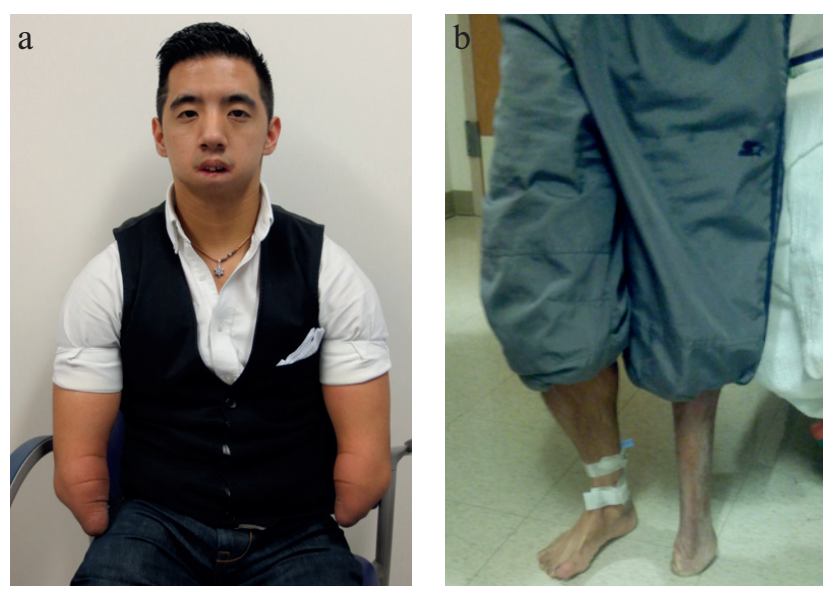

Fig. 2. a (left), b (right): Transverse deficiencies of the upper extremity below the elbow (left) and an absent foot below the upper ankle of the left lower extremity (right).

Table 1. Oromandibular Limb Hypogenesis Snydromes (OLHS): Hall classification ${ }^{14}$.

\begin{tabular}{|c|c|c|c|c|c|}
\hline & Type I & $\begin{array}{l}\text { Type II; Hypoglossia } \\
\text { with }\end{array}$ & $\begin{array}{l}\text { Type III; Glossopalatine } \\
\text { ankylosis with }\end{array}$ & $\begin{array}{l}\text { Type IV; Intraoral bands } \\
\text { and fusion with }\end{array}$ & Type V; Miscellaneous \\
\hline $\mathbf{A}$ & Hypoglossia & Hypodactylia & 1 & I & Hanhart syndrome \\
\hline B & Aglossia & Hypomelia & Hypoglossia & Hypoglossia & Charlie M syndrome \\
\hline C & & Hypodactylomelia & $\begin{array}{l}\text { Hypoglossia- } \\
\text { hypodactylia }\end{array}$ & $\begin{array}{l}\text { Hypoglossia- } \\
\text { hypodactylia }\end{array}$ & Pierre Robin syndrome \\
\hline D & & & $\begin{array}{l}\text { Hypoglossia- } \\
\text { hypomelia }\end{array}$ & $\begin{array}{l}\text { Hypoglossia- } \\
\text { hypomelia }\end{array}$ & Möbius syndrome \\
\hline $\mathbf{F}$ & & & $\begin{array}{l}\text { Hypoglossia- } \\
\text { hypodactylomelia }\end{array}$ & $\begin{array}{l}\text { Hypoglossia- } \\
\text { hypodactylomelia }\end{array}$ & Amniotic band syndrome \\
\hline
\end{tabular}



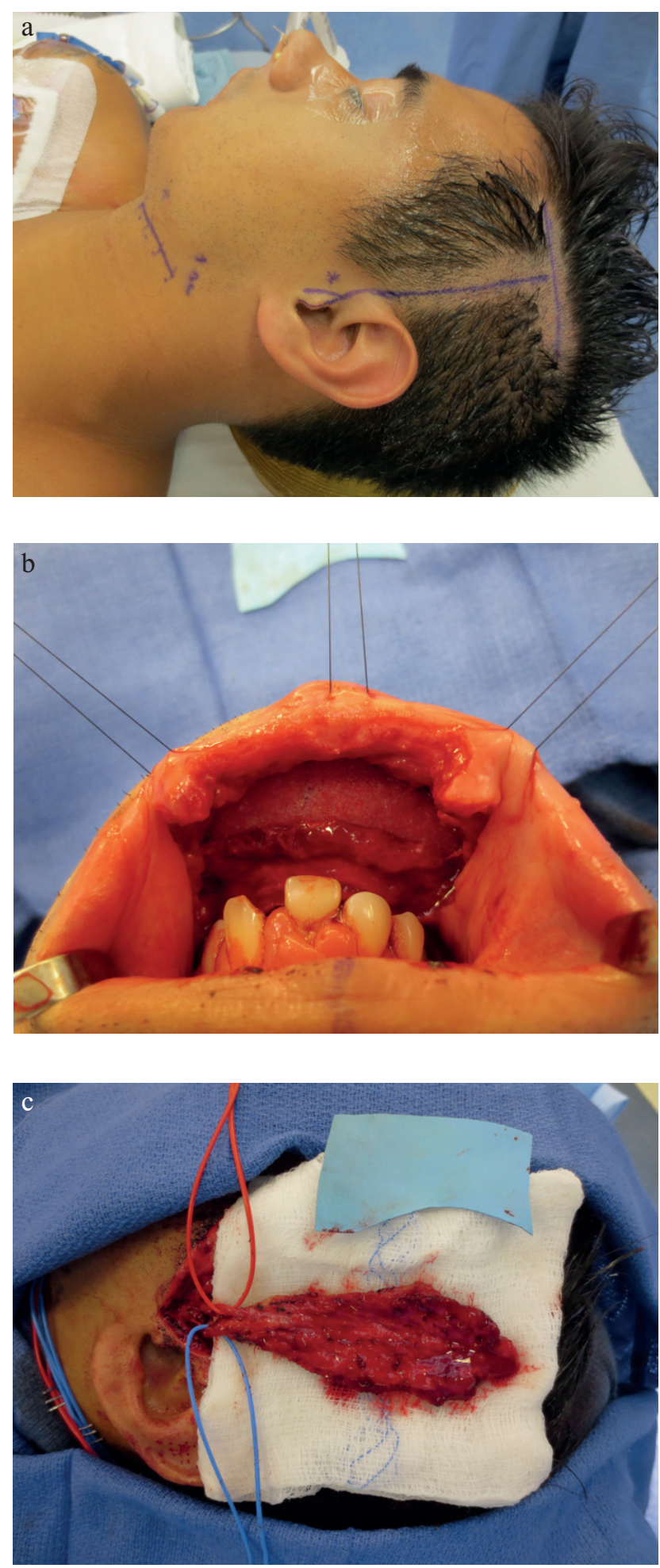

Fig. 3. a (left), b (middle), c (right): The left picture shows the preoperative incision lines for the temporoparietal free flap and its facial artery anastomosis. The middle picture demonstrates the chin implant before flap insertion (right picture).

\section{DISCUSSION}

Due to the low incidence rate, diagnosis of OLHS in general and particularly the concordant syndromes and phenotypes are very difficult to diagnose (Table 3). Apart from OLHS manifestations, other syndromes and groups of syndromes like acrocephalosyndactyly/acrocephalo-

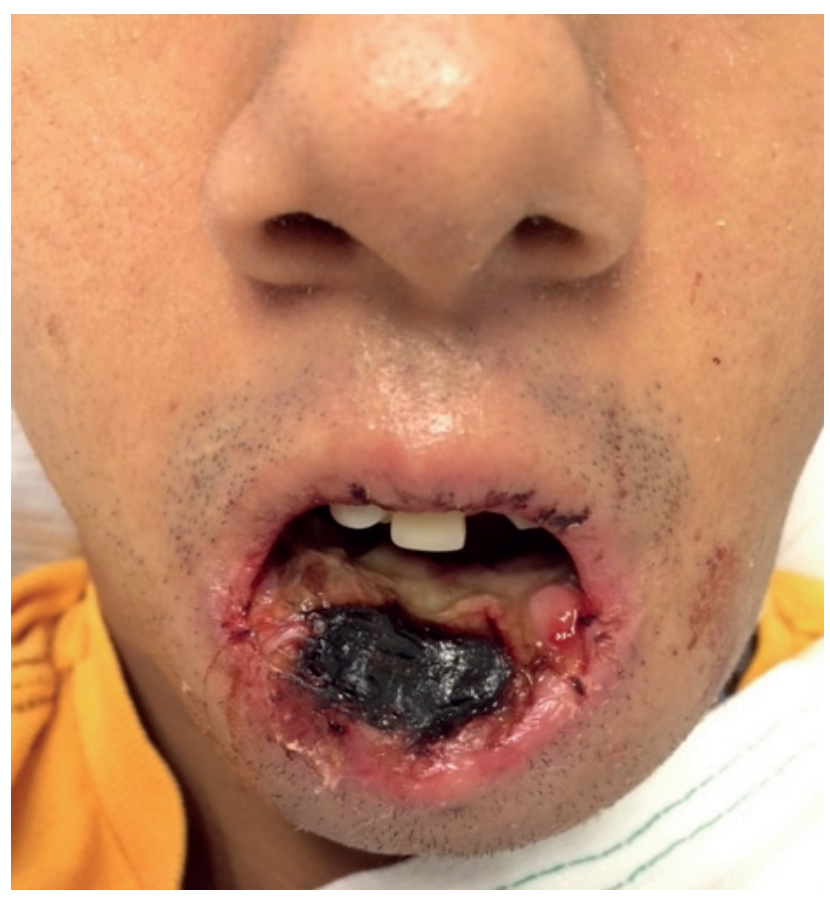

Fig. 4. The patient developed large pharyngeal blood clots after the first operation. The picture was taken before debridement and coagulation.

polysyndactyly syndromes, orofaciodigital syndromes, hypoglossia-hypodactylia syndrome, ankyloglossia superior syndrome and acrofacial dysostoses must be considered as general differential diagnoses.

Generally, patient history, physical examination for facial and skeletal malformations as well as genetic tests support a possible diagnosis. In our case, the patient history revealed maternal drug abuse, cleft palate, glossopalatine ankyloses but no genetic disorder. For these reasons, the patient was often diagnosed with either Robin- or amniotic band sequence in the past but this may overall attributed to highly variable phenotypes.

At our department, physical examination revealed characteristic specific skeletal (ectromelia) and facial (facial asymmetry, micrognathia, absent teeth) anomalies. Apart from differential diagnoses, (acrocephalosyndactyly/ acrocephalopolysyndactyly syndromes, orofaciodigital syndromes, acrofacial dysostoses) and clearly inherited causes (Cornelia de Lange syndrome, Smith-LemliOpitz syndrome, Weissenbacher-Zweymuller syndrome, Hanhart syndrome, Möbius syndrome), the diagnosis of Charlie M Syndrome was highly likely.

Normally, unusual cases like the Charlie M syndrome have no specific treatment recommendations which makes treatment demanding and must be patient-oriented. Thus, cosmetic interventions and their corresponding risks should be clearly anticipated. In our case, the patient's mandible function was severly impaired and impeded his daily life. On the positive side, the clearly visible facial dysmorphia could be also improved within the same surgical procedure. Arm and leg prosthetic treatment were not carried out given the possible effects on independent living. 
Table 2. Oromandibular Limb Hypogenesis Snydromes (OLHS): Chicarilli classification ${ }^{14}$.

\begin{tabular}{lllll}
\hline & $\begin{array}{l}\text { Type I; Micrognathia } \\
\text { (mandibular) with }\end{array}$ & $\begin{array}{l}\text { Type II; } \\
\text { Microglossia with }\end{array}$ & $\begin{array}{l}\text { Type III; } \\
\text { Dysgnathia with }\end{array}$ & $\begin{array}{l}\text { Type IV; } \\
\text { Miscellaneous }\end{array}$ \\
\hline A & Pierre Robin syndrome & Hypoglossia & Glossopalatine ankylosis & Möbius syndrome \\
B & Hanhart syndrome & Hypoglossia-hypodacytly & $\begin{array}{l}\text { Glossopalatine ankylosis- } \\
\text { hypodactyly }\end{array}$ & Charlie M syndrome \\
C & & & & (Amniotic band syndrome) \\
\hline
\end{tabular}

Table 3. Overview and phenotypical description of type V (Hall)/type IV (Chicarilli) OLHS syndromes without amniotic band syndrome (c.r.: case reports, AD: autosomal dominant, AR: autosomal recessive, XR: X-linked recessive).

\begin{tabular}{|c|c|c|c|c|}
\hline & Inheritance & Orofacial & Skeletal & Other \\
\hline Charlie M & $\begin{array}{l}\text { Sporadic, preva- } \\
\text { lence unknown }(<5 \\
\text { c.r. })\end{array}$ & $\begin{array}{l}\text { - facial asymmetry } \\
\text { - hypertelorism, telecanthus } \\
\text { - short philtrum } \\
\text { - micrognathia } \\
\text { - microstomia } \\
\text { - aglossia, hypoglossia } \\
\text { - absent teeth } \\
\text { - cleft palate } \\
\text { - gingival fibromatosis, } \\
\text { glossopalatine ankylosis }\end{array}$ & $\begin{aligned} \text { - } & \text { ectromelia } \\
\text { - etrodactyly, } & \text { oligodactyly }\end{aligned}$ & I \\
\hline Hanhart & $\begin{array}{l}\text { AD, sporadic; } \\
<1: 1.000 .000\end{array}$ & $\begin{array}{l}\text { - facial asymmetry } \\
\text { - hypertelorism, telecanthus } \\
\text { - short philtrum } \\
\text { - micrognathia } \\
\text { - microstomia } \\
\text { - aglossia, hypoglossia } \\
\text { - absent teeth } \\
\text { - cleft lip/palate } \\
\text { - glossolabial adhesion }\end{array}$ & $\begin{array}{l}\text { - ectromelia, normally } \\
\text { of all limbs } \\
\text { - etrodactyly, } \\
\text { oligodactyly }\end{array}$ & $\begin{array}{l}\text { - cases of gastroschisis } \\
\text { and pulmonary hypo- } \\
\text { plasia }\end{array}$ \\
\hline Möbius & $\begin{array}{l}\mathrm{AD} \text {, sporadic; preva- } \\
\text { lence unkwon }\end{array}$ & $\begin{array}{l}\text { - c.f. Hanhart } \\
\text { - CN } 7 \text { defect (major crite- } \\
\text { ria) } \\
\text { - CN III, IV, VI, IX, X, XII } \\
\text { defects possible } \\
\end{array}$ & - c.f. Hanhart & - c.f. Hanhart \\
\hline Pierre-Robin & $\begin{array}{l}\text { Sporadic, AD, AR, } \\
\text { XR; associated } \\
\text { with 17q23, SOX9; } \\
\text { 1:10.000 }\end{array}$ & $\begin{array}{l}\text { - cleft palate } \\
\text { - micrognathia } \\
\text { - glossoptosis }\end{array}$ & $\begin{array}{l}\text { - sometimes taped } \\
\text { fingers, clinodactyly } \\
(\mathrm{XR})\end{array}$ & $\begin{array}{l}\text { - } 20-40 \% \text { isolated, } \\
\text { otherwise part of } \\
\text { other syndromes like } \\
\text { Sticker or campomelic } \\
\text { dysplasia }\end{array}$ \\
\hline
\end{tabular}

Table 4. New classification of former OLHS: Oromandibular and limb hypogenesis malformations (OLHM).

\begin{tabular}{llll}
\hline \multicolumn{1}{l}{ Type I } & $\begin{array}{l}\text { Type II; Dysgnathia } \\
\text { with }\end{array}$ & $\begin{array}{l}\text { Type III; Dysgnathia and glossopalatine } \\
\text { ankylosis/intraoral bands of fusion with }\end{array}$ & Type IV; Miscellaneous \\
\hline $\begin{array}{l}\text { A } \begin{array}{l}\text { Hypoglossia/ } \\
\text { aglossia }\end{array} \\
\text { B } \begin{array}{l}\text { Hypoglossia/ } \\
\text { aglossia-hypodactyly }\end{array}\end{array}$ & $\begin{array}{l}\text { Hypoglossia/aglossia- } \\
\text { hypodactyly }\end{array}$ & $\begin{array}{l}\text { Hypoglossia/aglossia- } \\
\text { hypodactyly }\end{array}$ & Hanhart syndrome \\
C & & Möbius syndrome \\
D & & $\begin{array}{l}\text { Charlie M syndrome type I } \\
\text { (Kaplan) }\end{array}$ \\
E & & Charlie M syndrome type II \\
\hline
\end{tabular}


Based on descriptions of the Charlie M syndrome, glossopalatine ankylosis has not been described as part of the anomaly so $\mathrm{far}^{4-6}$. This may because only incomplete and debatable case reports of the Charlie $\mathrm{M}$ syndrome have been published in the literature so far ${ }^{46,15}$. Grippaudo et al. described a case with phenotypical malformations of the face and extremities similar to the Charlie M syndrome but concluded that glossopalatine ankylosis was an entirely new malformation ${ }^{4}$. Our patient also revealed a history of glossopalatine ankylosis which we classify due to otherwise similar characteristics, as a new subtype of the Charlie M syndrome.

There have been several attempts to explain the emergence of OLHS, Charlie M syndrome and glossopalatine ankylosis ${ }^{4-6,13,16-18}$. Generally, defects in facial and limb differentiation must be attributed to days 28-63 of the embryologic period ${ }^{4,6}$. The upper extremity development begins by day 32, differentiates into arm, forearm and hand at day 37 and finally appears differentiated when digits separate by day $46^{16}$. Growth of the lower extremity is delayed by around one week.

In addition to confirmed inheritance of some OLHS malformations and syndromes (e.g. Möbius, Hanhart, Pierre Robin partially), most cases occur sporadically ${ }^{4,16}$. The inheritance of mutated Msx2, a homebox gene in particular, is associated with craniofacial and limb malformations ${ }^{4}$. Beside external uterine environmental factors such as drug abuse (e.g. thalidomide, chemotherapy), maternal illness, vitamin deficiency and radiation, vascular interferences (e.g. malformations or disruptions) and rupture of the amnion are discussed as internal causes ${ }^{4,13,16}$. For example, Bavinck et al. associated disruptions of the subclavian artery with extremity hypoplasia but not facial malformations ${ }^{19}$. Poswillo and McKenzie et al. associated first and second branchial arch syndromes with stapedial artery anomalies ${ }^{20-22}$. However, these facts do not explain glossopalatine ankylosis in its pathogenesis.

There are two theories which might explain the development of glossopalatine ankylosis. The first theory hypothesizes the appearance of intraoral bands by the persistence of the buccopharyngeal membrane (BPM) (ref. ${ }^{4,16-18)}$. The BPM develops when the intraembryonic mesoderm does not invade all parts of the intraembryonic disc which results in separation of the stomatodeum entoderm and the foregut ectoderm up to day 26 (ref. ${ }^{16,17)}$. Afterwards, tension of the BPM becomes greater by rapid growth of the pharynx, tongue and facial structures, which results in breakdown of the BPM (ref. ${ }^{17-18}$ ). The second theory assumes the persistence of a subglossopalatal membrane or ectopic membranes, which can be present between the sixth and eighth week of the embryonic development and normally disappear by the dropdown of the tongue around the ninth week ${ }^{4,16-18}$. Therefore, either the persistence of membranes, failure of the tongue to drop down or both can cause membranous fusion between the upper and lower jaw.

In our case, the intake of birth abortion pills might have affected the normal embryological development and therefore appearance of the Charlie M syndrome. Since family history emphasizes no occurrence of malformations and other OLHS phenotypes and syndromes, the diagnosis with Charlie M syndrome seems most appropriate (referred to as type II, Table 4).

As a result from our case and literature review, we suggest to adjust the Chicarilli and Hall classifications into a more phenotypical descriptive classification. On the one hand, Hall distinguished between different appearances of hypoglossia, aglossia, hypodactyly, hypomelia, hypodactylomelia, combinations of the named malformations and a group of miscellaneous syndromes, which are generally confusing and difficult to use in daily routine (Table 1). On the other hand, Chicarilli focused on the embryologic emergence of OLHS malformations, which divides similar inherited and visible phenotypes in different types (e.g. Hanhart and Möbius syndrome) (Table 2). Therefore we consequently classified the appearance hypoglossia/ aglossia(-hypodactyly) (type I) with dysgnathia (type II) and dysgnathia with glossopalatine ankylosis/intraoral bands of fusion (type III) (Table 4). Our miscellaneous type IV group contains Hanhart syndrome, Möbius syndrome, Robin sequence and Charlie M syndrome type I (Kaplan, no glossopalatine ankylosis) and type II (glossopalatine ankylosis). Furthermore, we recommend changing the Pierre Robin syndrome into Robin sequence and complete deletion of the amniotic band syndrome (or sequence) from the classification because it only randomly results in malformations of the face and extremities. Finally, renaming OLHS into "Oromandibular and limb hypogenesis malformations” (OLHM) seems most appropriate due to the synopsis of different syndromes, sequences and anomalies in one classification system.

\section{CONCLUSION}

Despite various malformations of the face and extremities, treatment of OLHS and the Charlie M syndrome must always be demand-oriented. Although our patient suffers from several serious congenital amputations, he only wanted to have his facial profile to be improved.

Up to now, inheritance for the Charlie M syndrome seems most unlikely, so that research should rather concentrate on possible triggering factors and their disruptive potential with embryologic development.

Beside the improved classification table of former OLHS into "Oromandibular and limb hypogenesis malformations" (OLHM), a more profound overview regarding malformations affecting the face and extremities is needed to be done. This way, faster, cost-efficient and reliable diagnoses can be provided.

Author contributions: OJ, BL: manuscript writing and literature search; RS, HH, RF, MH, AT: literature search, supervision and proofreading.

Conflict of interest statement: The authors state that there are no conflicts of interest regarding the publication of this article. 


\section{REFERENCES}

1. Brockmann K, Backes H, Auber B, Kriebel T, Stellmer F, Zoll B. Overlap of Moebius and oromandibular limb hypogenesis syndrome with gastroschisis and pulmonary hypoplasia. Am J Med Genet A 2009;149(12):2832-7

2. Cappellette M, Ferreira da Costa CM, Nobrega Md, Oliveira WCd, Weckx LLM. Oromandibular and limb hypogenesis syndrome: treatment report. Oral Surg Oral Med Oral Pathol Oral Radio 2013;116(4):e230-6.

3. Souza-Dias CRd, Goldchmit M. Further considerations about the ophthalmic features of the Möbius sequence, with data of 28 cases. Arq Bras Oftalmol 2007;70(3):451-7.

4. Grippaudo FR, Kennedy DC. Oromandibular-limb hypogenesis syndromes: a case of aglossia with an intraoral band. Br J Plast Surg 1998;51(6):480-3.

5. Herrmann J, Pallister PD, Gilbert EF, Vieseskul C, Bersu E, Pettersen $J C$, et al. Studies of malformation syndromes of man XXXXI B: nosologic studies in the Hanhart and the Möbius syndrome. Eur J Pediatr 1976;122(1):19-55

6. Kaplan P, Cummings C, Fraser FC. A "community" of face-limb malformation syndromes. The J Pediatr 1976;89(2):241-7.

7. Meundi MA, Nair GR, Sreenivasan P, Raj AC. Oromandibular Limb Hypogenesis Syndrome Type IIB: Case Report of HypoglossiaHypodactyly. Case Rep Dent 2013;2013:370695.

8. Miller MT, Ray V, Owens P, Chen F. Möbius and Möbius-like syndromes (TTV-OFM, OMLH). J Pediatr Ophthalmol Strabismus 1989;26(4):176-88.

9. Miller MT, Strömland K. The möbius sequence: a relook. J AAPOS 1999;3(4):199-208.

10. Sturm V, Michels R, Menke MN, Landau K. Diagnose und Therapie okulomotorischer Defizite bei Patienten mit Möbius-Sequenz. Ophthalmologe. 2010;107(8):708-12. (In German)

11. Yamada A, Konno N, Imai Y, Saitou C, Kochi S. Treatment of hypoglossia-hypodactyly syndrome without extremeity anomalies. Plast Reconstr Surg 2000;106(2):274-9.

12. Emmanouil-Nikoloussi E, Kerameos-Foroglou C. Congenital syndromes connected with tongue malformations. Bull Assoc Anat (Nancy) 1992;76(235):67-72.

13. Preis $S$, Majewski F, Hantschmann R, Schumacher $H$, Lenard HG. Goldenhar, Möbius and hypoglossia-hypodactyly anomalies in a patient: syndrome or association? Eur J Pediatr 1996;155(5):385-9.

14. Chicarilli ZN, Polayes IM. Oromandibular limb hypogenesis syndromes. Plast Reconstr Surg 1985;76(1):13-24.

15. Bonioli E, Sbolgi P, Bernaola E, Pacciani G, Cottafava F. La sindrome "Charlie M." nuova entità clinica? Descrizione di un caso. Minerva Pediatr 1980;32(10):699-702.

16. Spivack J, Bennett JE. Glossopalatine ankylosis. Plast Reconstr Surg 1968;42(2):129-36.

17. Ooi EH, Khouri Z, Hilton M. Persistent buccopharyngeal membrane in an adult. Int J Oral Maxillofac Surg 2005;34(4):446-8.

18. Gartlan MG, Davies J, Smith RJ. Congenital oral synechiae. Ann Oto Rhinol Laryngol 1993;102(3 Pt 1):186-97.

19. Bavinck JN, Weaver DD. Subclavian artery supply disruption sequence: hypothesis of a vascular etiology for Poland, Klippel-Feil, and Möbius anomalies. Am J Med Genet 1986;23(4):903-18.

20. McKenzie J. The first arch syndrome. Arch Dis Child 1958;33(171):47786

21. McKenzie J. The first arch syndrome. Dev Med Child Neurol 1966;8(1):55-66.

22. Poswillo $D$. The pathogenesis of the first and second branchial arch syndrome. Oral Surg Oral Med Oral Pathol 1973;35(3):302-28. 